\title{
Five-Year Clinical and Radiographic Outcomes After Minimally Invasive Sacroiliac Joint Fusion Using Triangular Implants
}

\author{
Leonard Rudolf ${ }^{1}$ and Robyn Capobianco ${ }^{*}, 2$ \\ ${ }^{1}$ Alice Peck Day Memorial Hospital, 17 Alice Peck Day Drive, Suite C, Lebanon, NH 03766, USA \\ ${ }^{2}$ SI-BONE, Inc., 3055 Olin Ave, Suite 2200, San Jose, CA 95128, USA
}

\begin{abstract}
Object: Previous reports of minimally invasive (MIS) sacroiliac (SI) joint fusion for low back, SI joint, and buttock pain secondary to SI joint disorders have shown favorable short- and mid-term outcomes. Herein we present 5year clinical and radiographic outcomes after MIS SI joint fusion using a series of triangular porous titanium plasma spray (TPS) coated implants.

Methods: Consecutive patients treated with MIS SI joint fusion for degenerative sacroiliitis and/or sacroiliac joint disruptions between October 2007 and March 2009 were evaluated. Pain on VAS, an SI joint specific survey and Oswestry Disability Index (ODI) were administered. X-ray and CT scans were obtained to assess the implants.

Results: Of 21 patients treated, 17 were available for the study. Mean age was 58 years (range 36-85), 77\% were female and $47 \%$ had prior lumbar spinal fusion. Pain on VAS improved from 8.3 at baseline to 2.4 at 5 years; $88 \%$ of patients reached Substantial Clinical Benefit. Mean ODI score at 5 years was 21.5 (SD 22.7). Patient satisfaction achieved at 12 months was maintained for 5 years $(82 \%)$. A qualitative review of $\mathrm{x}$-ray and CT imaging showed increased bone density immediately adjacent to all implants, intra-articular osseous bridging in $87 \%$ of patients and no evidence of implant loosening or migration.

Conclusion: Long-term clinical and radiographic outcomes after MIS SIJ fusion are favorable. Clinical improvements observed at 12 months postoperatively were maintained at 5 years. There was no evidence of long-term complications, implant loosening or migration. Patients who did not achieve large improvements were affected by multiple severe concomitant degenerative conditions of the lumbar spine, pelvis, and/or hip.
\end{abstract}

Keywords: Arthrodesis, minimally invasive surgery, previous spine surgery, sacroiliac joint, SI joint fusion.

\section{INTRODUCTION}

Chronic lower back pain is well known as a public health epidemic. In highly developed countries, it is one of the top 3 causes of degradation in quality adjusted life years, along with ischemic heart disease and chronic obstructive pulmonary disease [1]. While lumbar spine pathology is an important cause of chronic lower back pain, substantial evidence suggests that not all low back pain is due to lumbar spine pathology. The SI joint is thought to be the source of pain in up to $30 \%$ of patients evaluated for chronic lower back pain [2-5]. Disorders of the SI joint may be the result of trauma, pregnancy, inflammatory arthritis, osteoarthritis or degeneration of the joint either de novo or after lumbar spinal fusion [6]. In the case of lumbar spinal arthrodesis, sacroiliac joint pathology may explain delayed postoperative pain or a failure for the patient to experience symptom improvement in the early postoperative period (failed back surgery syndrome) [7, 8]. Diagnosing the SI joint as the primary or sole pain generator (PG) can be complex as patients often present with a combination of low back, groin,

*Address correspondence to this author at the SI-BONE, Inc., 3055 Olin Ave, Suite 2200, San Jose, CA 95128, USA; Tel: +1-408-207-0700; Fax: +1-408-516-9663; E-mail: rcapobianco@si-bone.com gluteal, and/or leg pain and the symptom profile may mimic other disorders of the lumbar spine and hip [2, 9]. Additionally, some patients present with more than one pain generator within the lumbar spine-SI joint-hip axis, making the identification of the primary versus secondary pain generators more challenging [3]. Furthermore, SI joint imaging studies are typically neither sensitive nor specific to abnormalities in the absence of trauma, tumor, ankylosing spondylitis, or infection [10].

SI joint pain can be debilitating and treatment with nonoperative care is often unsuccessful. The impact of pain on persons living with the disease is similar to that associated with other prominent orthopedic conditions routinely treated surgically [11]. Furthermore, the economic burden of nonoperative care is significant for Medicare as well as commercial payer entities with a 5-year estimated cost of $\$ 270$ million for Medicare beneficiaries and a 3-year estimated cost of $\$ 1.6$ billion per 100,000 commercial covered lives $[12,13]$.

Surgical treatment options for SI joint disorders have been unattractive until relatively recently. Open arthrodesis, commonly performed throughout the 1900 s, is now reserved primarily for traumatic pelvic ring fractures due to the invasiveness of the procedure, coupled with a high morbidity rate [14-16]. In recent years, several minimally invasive 
techniques for fusing the SI joint have been introduced into the surgical repertoire [17-21]. MIS SI joint fusion for certain SI joint disorders (degenerative sacroiliitis and SI joint disruptions), specifically using a series of triangular titanium implants, has been shown to result in lower morbidity, including shorter operating times and hospital stays, fewer complications, a lower reoperation rate, and higher gains in patient quality of life compared to the open surgical method, as evidenced by a recent comparative cohort study [22].

The current body of medical literature substantiates positive short to mid-term clinical outcomes [17, 23-25]. However, no long-term clinical or radiographic outcomes have been published to date. Herein we report 5-year clinical effectiveness, safety and radiographic outcomes in patients treated with MIS SI joint fusion for degenerative sacroiliitis or sacroiliac joint disruptions using a series of triangular, porous titanium plasma spray (TPS) coated implants (iFuse Implant System ${ }^{\mathbb{B}}$, SI-BONE, Inc., San Jose, CA) from a single center.

\section{METHODS}

All consecutive patients who underwent MIS SI joint fusion between October 2007 and March 2009 at a single center were identified. Prior to surgery, all patients were diagnosed with either degenerative sacroiliitis and/or SI joint disruptions using a detailed history, combination of physical provocative maneuvers specific to the SI joint, image-guided intra-articular SI joint injections and various imaging modalities [17]. MIS SI joint fusion was performed in all patients by placing a series of implants laterally across the SI joint, as previously described $[17,23]$. Patients were contacted and asked to participate in a long-term evaluation, which included a clinical exam as well as an optional radiographic imaging component. Patients signed a studyspecific, IRB-approved consent form before beginning any study-related activity.

Patients were asked to reveal and discuss any further surgical treatment they received for SI joint, lumbar spine, pelvic or hip disorders. A series of patient reported outcome instruments, described below, was also administered. Participants who resided outside of a reasonable travel distance were given the opportunity to provide responses by phone or mail. Patients who consented to the radiographic component of the study had both plain film radiographs (outlet and anteroposterior (AP) views) and computed tomography (CT) scans of the pelvis. These imaging tests were used to assess implant position, evidence of lucency adjacent to the implant, qualitative increase in bone density adjacent to the implant, and presence of intra-articular osseous bridging. The 5-year images were compared to those previously acquired closest to the one-year follow-up interval.

Data extracted from the medical charts included demographics, diagnosed pain generators in the lumbar spine-SI joint-hip axis, pain treatments received, perioperative measures, adverse events, one-year imaging studies, and previously administered patient reported outcomes at 12- and 24-months postoperatively, described below.

\section{Patient Reported Outcome Measures}

Pain and functional outcomes were assessed in a prospective manner pre-operatively and at 12-, 24- and 60-months postoperatively. Level of pain was assessed using a $0-10$ visual analog scale (VAS). Prior to the initial experience with the surgical procedure, a 9-question SI jointrelated health outcomes survey was created with response domains taken from both the SF-36 and Oswestry Disability Index (ODI) (Fig. 1): pain level, the ability to perform light, moderate and vigorous activities, quality of sleep, lifting ability, happiness, social activities, and the effect of pain on social life [17]. A numerical rating scale of $0-10$ with 0 representing no pain or difficulty and 10 representing the worst pain imaginable or severe difficulty was used for all domains. Satisfaction with surgery was assessed in a binary fashion (yes or no) by asking if the patient would have the same surgery again for the same result.
1. How much pain are you in at this time?
2. How well are you able to perform light activities like walking a block or dressing yourself?
3. How well are you able to perform moderate activities like playing golf, walking half a mile, or dancing?
4. How well are you able to perform vigorous activities like running or moving furniture?
5. How much is your sleep disturbed by pain at this time?
6. How well are you able to lift items off the floor at this time?
7. How would you assess your level of happiness at this time?
8. How interested are you in socializing at this time?
9. Because of pain, how much is your socializing limited at this time?

Fig. (1). SI Joint outcomes survey.

The SI joint-related health outcomes survey and VAS were administered preoperatively and at 12 - and 60-months postoperatively. At 24 months, patients were contacted to assess SI joint pain on VAS. The ODI was administered at the 60-month visit only. Satisfaction and safety events were collected at all postoperative time points.

Demographic variables were tabulated and expressed as frequency and means with standard deviation, where appropriate. A repeated measures analysis of variance (ANOVA) was used to compare VAS pain scores from baseline to all postoperative time points. A paired t-test was used to assess improvement from baseline to the 60-month time point on the SI joint survey. An unpaired t-test was performed to assess the effect of sex and history of prior lumbar spinal fusion on outcomes. Statistical analyses were performed using R software [26]. Clinical improvement was defined using previously validated minimum clinically important difference (MCID) and substantial clinical benefit (SCB) values for back pain on VAS. MCID is defined as a change of $>2.0$ points and SCB is defined as a 2.5-point decrease or a raw score of $<3.5[27,28]$.

Institutional Review Board approval was obtained before beginning this study. 


\section{RESULTS}

Of 21 consecutive patients who underwent MIS SI joint fusion, 17 were available for follow-up and form the analysis cohort. Of those not available, 2 had died unrelated to spine conditions, one was lost to follow-up and one suffered a severe neck trauma rendering the patient quadriplegic and unable to provide relevant data. All available patients participated inthe clinical portion of the study and 15 of 17 $(88 \%)$ agreed to participate in the radiographic component.

Mean subject age was $58( \pm 14)$ years (range $36-85), 77 \%$ were female and $47 \%$ had undergone lumbar spinal fusion prior to SI joint fusion (Table 1). Slightly more subjects had the right SI joint treated (53\%) compared to the left (41\%), and one patient underwent bilateral treatment. Mean operating time was $65( \pm 18)$ minutes, range (43-110). There were no intraoperative complications. Postoperative events, which primarily included hematoma (1), cellulitis (2), and deep infection secondary to diverticulitis (1), were previously reported in detail [17].

Table 1. Demographics and Peri-operative measures.

\begin{tabular}{|c|c|c|}
\hline \multicolumn{3}{|l|}{$\mathrm{N}=17$} \\
\hline Age (years), mean $( \pm \mathrm{SD})$ & \multicolumn{2}{|c|}{$58( \pm 13.6)$, range $36-85$} \\
\hline Female sex & \multicolumn{2}{|l|}{$13(77 \%)$} \\
\hline Prior lumbar spinal fusion & \multicolumn{2}{|l|}{$8(47 \%)$} \\
\hline \multirow[t]{3}{*}{ Side treated } & Right: & $53 \%(9)$ \\
\hline & Left: & $41 \%(7)$ \\
\hline & Bilateral: & $6 \%(1)$ \\
\hline Operating time (minutes), mean $( \pm \mathrm{SD})$ & \multicolumn{2}{|c|}{65 (SD 18), range 43-110 } \\
\hline Implants placed & \multicolumn{2}{|l|}{54} \\
\hline
\end{tabular}

\section{Clinical Outcomes}

Improvement in pain was clinically and statistically significant at all follow-up intervals compared to baseline (all $\mathrm{p}<0.001)$ (Table 2). All subjects who reached MCID also reached SCB. The percentage of patients who achieved both MCID and SCB remained high at each time point $(77 \%$, $82 \%$, and $88 \%$ at $12-, 24-$ and 60 -month visits, respectively). No statistical effect was found for sex, or history of lumbar fusion on pain improvement at any time point.

Table 2. VAS clinical outcomes.

\begin{tabular}{|l|c|c|c|c|}
\hline \multicolumn{1}{|c|}{ VAS } & Mean (SD) & Change & MCID & rANOVA \\
\hline \hline Baseline & $8.3(1.4)$ & & & \\
\hline $12 \mathrm{mo}$ & $3.4(2.4)$ & -5.1 & $13(76.5 \%)$ & $\mathrm{p}<0.001$ \\
\hline $24 \mathrm{mo}$ & $1.4(2.6)$ & -7.0 & $14(82.4 \%)$ & $\mathrm{p}<0.001$ \\
\hline $60 \mathrm{mo}$ & $2.4(2.2)$ & -5.9 & $15(88.2 \%)$ & $\mathrm{p}<0.001$ \\
\hline
\end{tabular}

At 60 -months, statistically significant improvement was seen in 6 of 8 domains of the SI joint survey instrument (Table 3): the ability to perform light, moderate and vigorous activities, sleep disturbance caused by pain, overall happiness, and the effect of pain on social life. The ability to perform light, moderate and vigorous activities showed continual improvement from 12 months to the 5-year time interval.

Patient satisfaction scores obtained at the 12-month interval were unchanged at 2- and 5-years postoperatively; $82 \%(14 / 17)$ would have the same surgery again for the same result at all time points.

ODI scores were obtained at the 5-year follow-up only (Table 4). Mean (SD) ODI score was 21.5 (22.7). Fairbank categorized scores in terms of degree of disability, with 0-20 representing minimal disability and 21-40 representing moderate disability requiring conservative care only [29]. Results show the majority (71\%) of subjects are living with minimal or moderate disability.

\section{Imaging Studies}

Pelvic AP and outlet view plain films radiographs and a pelvic computed tomography (CT) scan were performed on 15 subjects; 45 implants were assessed. Imaging studies obtained at 5 years were compared to available studies acquired as close as possible to the one-year postoperative time point.

A qualitative comparison of 1- and 5-year pelvic plain film radiographs, including AP and outlet views, revealed no change in implant position (Fig. 2). CT scans of the pelvis with axial, sagittal, and coronal reconstructions documented increased bone density circumferentially along three implant walls for all implants on both the iliac and sacral segments. Evidence of osseous bridging across the SI joint was clearly seen on 13 of $15(87 \%)$ of patients (Fig. 3). On x-ray, what appeared to be full-length lucency (absence of bone adjacent to an implant) along the wall of the implant was consistently observed on at least one implant in all patients on AP view. However, this observation was not evident on the outlet view. Upon review of CT imaging, this apparent lucency was confirmed to be an artifact (Fig. 4). Assessment and comparison of CT scans at 1- and 5-years revealed a consistent pattern of artifacts at the corners and periodically along the wall of an implant, which were non-progressive and unchanged in equivalent projections on the axial, sagittal and coronal sections. A small area of true focal lucency was observed on CT scans in 4 patients; along the superior edge of the most cranial implant on the iliac side in 3 patients, and on the superior edge of the most caudal implant on the iliac side in one patient (Fig. 5). Other findings included a regular pattern of sclerotic bone response at the implant entry point in the ilium, on primarily the superior implant (Fig. 6). A detailed explanation of the physics of CT imaging of triangular titanium implants is outside the scope of this manuscript and will be reported separately.

\section{Non-Responders}

Three subjects in the current cohort did not improve satisfactorily. To understand why these patients failed to improve and to refine patient selection criteria for MIS SI joint fusion, an in-depth interview was performed for each patient. Patient vignettes are described below. 
Table 3. SI joint-related health outcomes survey. Each category was rated on a $0-10$ scale where $0=$ no pain or no difficulty and $10=$ worst pain imaginable or severe difficulty .

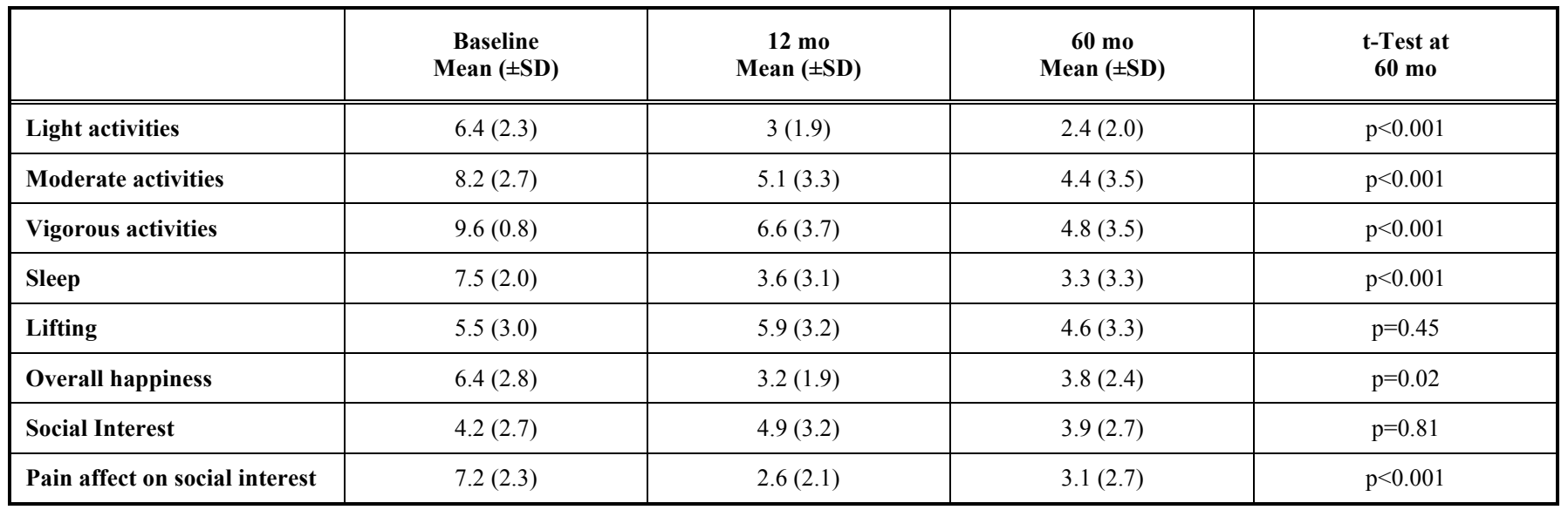

Table 4. ODI outcomes.

\begin{tabular}{|l|c|}
\hline Cohort mean $( \pm$ SD) ODI score at 5 years & $21.5( \pm 22.7)$ \\
\hline Category of Disability* & $\mathrm{N}(\%)$ \\
\hline $\begin{array}{l}0-20 \%: \text { minimal: } \\
\text { The patient can cope with most living activities. Usually no treatment is indicated apart from advice on lifting sitting and exercise }\end{array}$ & $10(59 \%)$ \\
\hline $\begin{array}{l}21-40 \%: \text { moderate: } \\
\text { The patient experiences more pain and difficulty with sitting lifting and standing. Travel and social life are more difficult and they may } \\
\text { be disabled from work. Personal care sexual activity and sleeping are not grossly affected and the patient can usually be managed by } \\
\text { conservative means. }\end{array}$ & $2(12 \%)$ \\
\hline $\begin{array}{l}41-60 \%: \text { severe: } \\
\text { Pain remains the main problem in this group but activities of daily living are affected. These patients require a detailed investigation. }\end{array}$ & $4(23 \%)$ \\
\hline $\begin{array}{l}61-80 \%: \text { crippled: } \\
\text { Back pain impinges on all aspects of the patient's life. Positive intervention is required. }\end{array}$ & $1(6 \%)$ \\
\hline
\end{tabular}

*Categorization from Fairbank JC, Pynsent PB. Spine 2000; 25(22): 2940-2952.
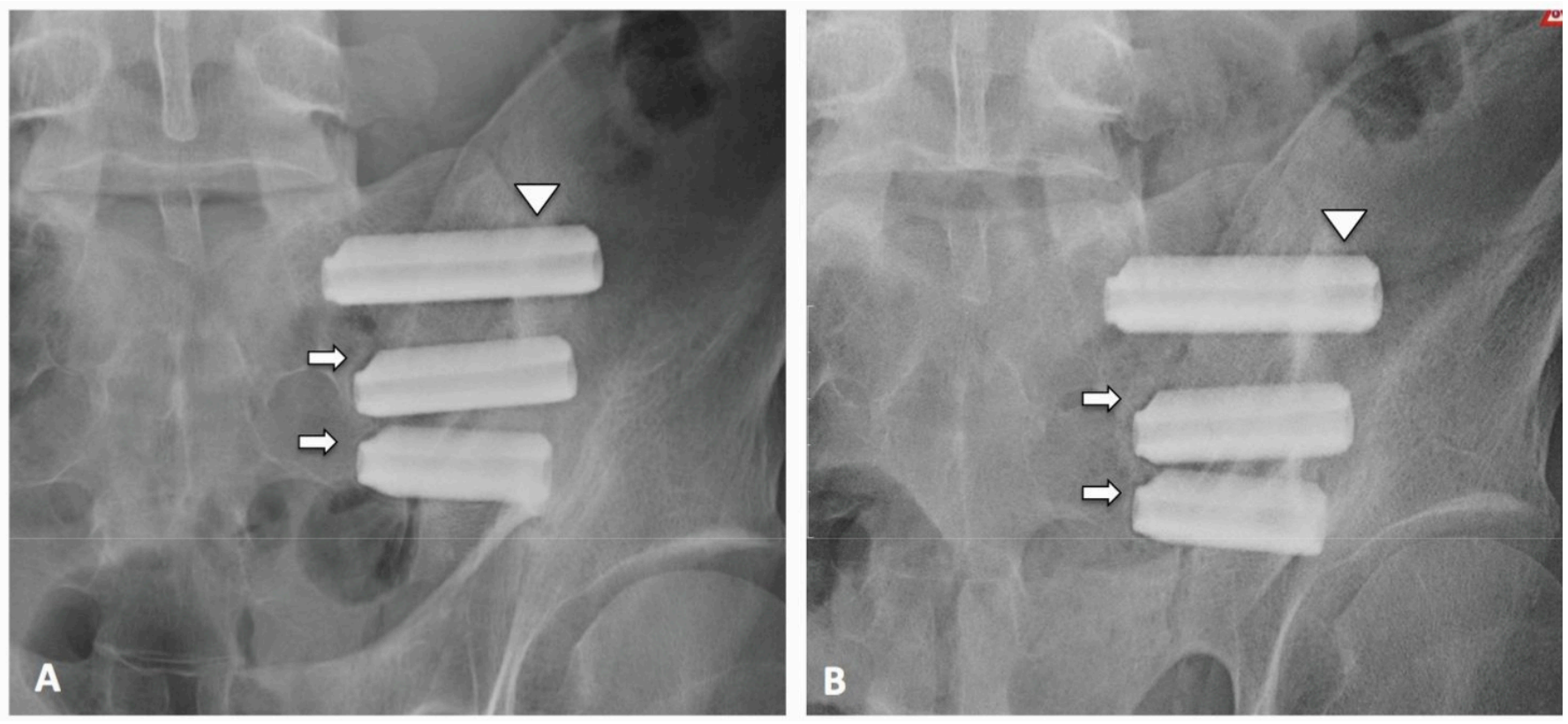

Fig. (2). AP radiographs obtained at A) 1 year and at B) 5 years on the same patient. Lucency is observed along the wall (triangle) and shoulder (arrow) of the implants at 1 year and remains unchanged at 5 years, indicative of artifact rather than lucency. 

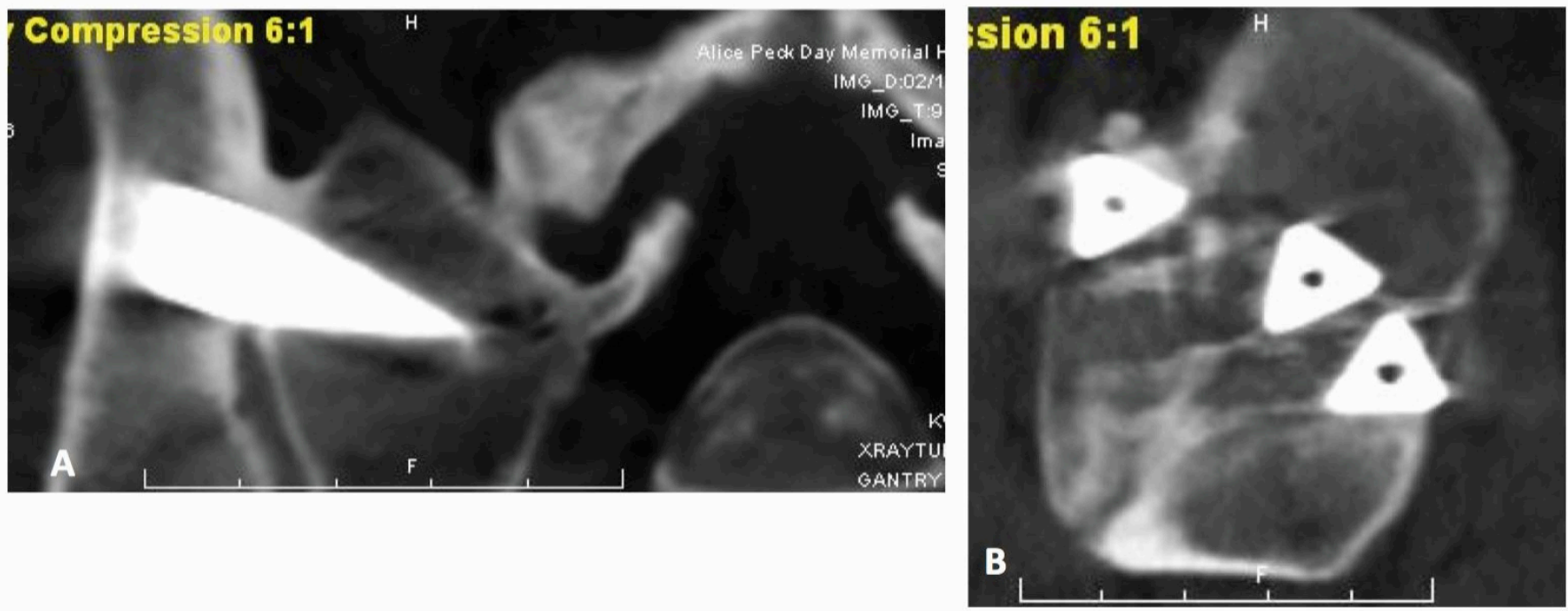

Fig. (3). A) Axial and B) sagittal CT scan obtained at 5 years showing favorable placement of the implants and intra-articular osseous bridging.

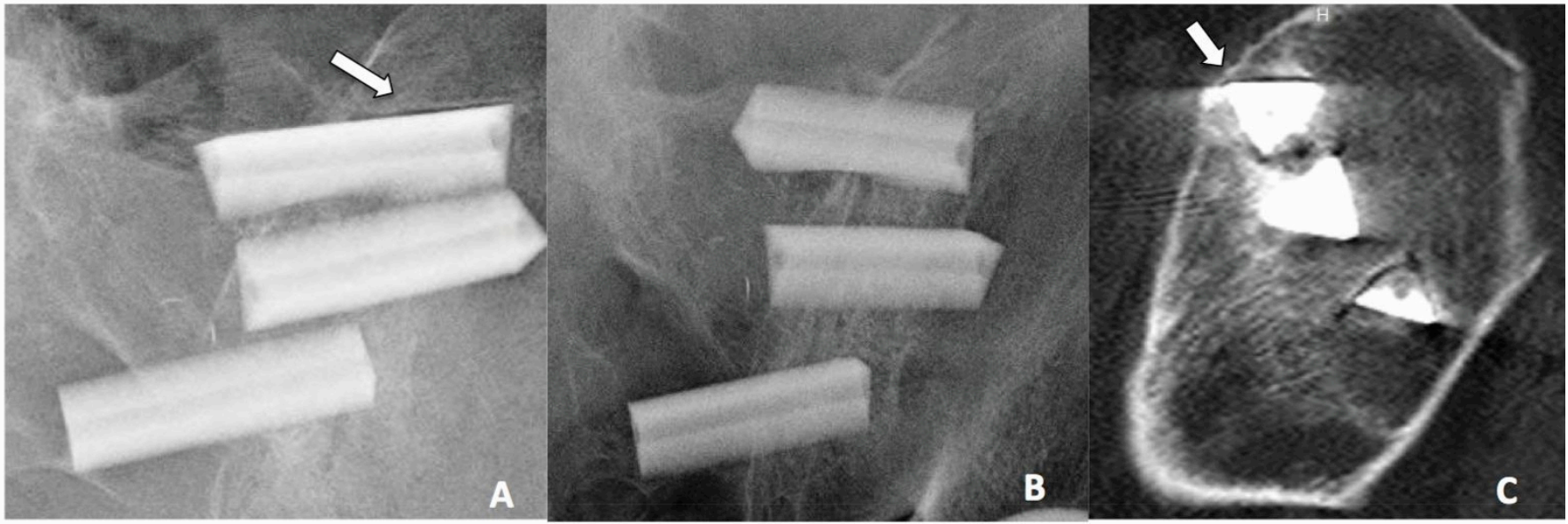

Fig. (4). Plain radiographs showing apparent lucency along the wall of the superior implants on the pelvic AP view (A), but not on the pelvic outlet view (B). Sagittal view on CT scan (C) confirms the "lucency" as an artifact.

Subject 1012 is a 72-year old woman who presented to the clinic complaining of low back and pelvic pain. The subject's history included a successful total knee replacement as well as L3-L5 arthrodesis for degenerative thoracolumbar scoliosis, symptomatic spondylosis and spondylolisthesis. At baseline, the lumbar spine and SI joint were confirmed as pain generators using physical and clinical exam, imaging studies, and injections as appropriate. Non-operative management was employed for lumbar spinal pain. Based on the pain improvement associated with imageguided intra-articular SI joint injection, MIS SI joint fusion was performed without postoperative complications. After surgery, she continued to have persistent back pain and buttock pain with walking. Subsequent imaging studies revealed a progression of her scoliotic curve above L3 with pelvic obliquity and clinical exam suggested multiple pain generators including thoracolumbar spine and degenerative joint disease of the hip.

Pelvic and spinal radiographs at the 5-year visit, and comparison to imaging at 1-year, revealed her SI implants to be intact with no signs of loosening, and a progression of spondylosis at levels above L3. The 5-year pelvic CT scan showed increased bone density along the walls of the implants, suggestive of biological fixation of the implants in bone. There were no imaging findings to suggest implant failure as explanation for the subject's residual pain.

In addition to her SI joint problems, this patient suffers from multiple pain generators including hip dysfunction secondary to pelvic obliquity and spondylosis associated with degenerative scoliosis. A review of this case provokes concern that the symptomatology of other pain generators may have overshadowed any potential improvement after SI joint treatment. Results from a single image guided intraarticular SI joint injection may be vulnerable to misinterpretation in the context of multiple pain generators. Some patients may benefit from a second injection. Positive results on the second injection will confirm the SI joint as the primary PG. However, an equivocal response of less than $75 \%$ pain reduction would suggest the SI joint as a secondary PG [30]. No pain improvement rules out the SI and indicates that other PGs in the lumbar spine-SI joint-hip axis need further investigation. 

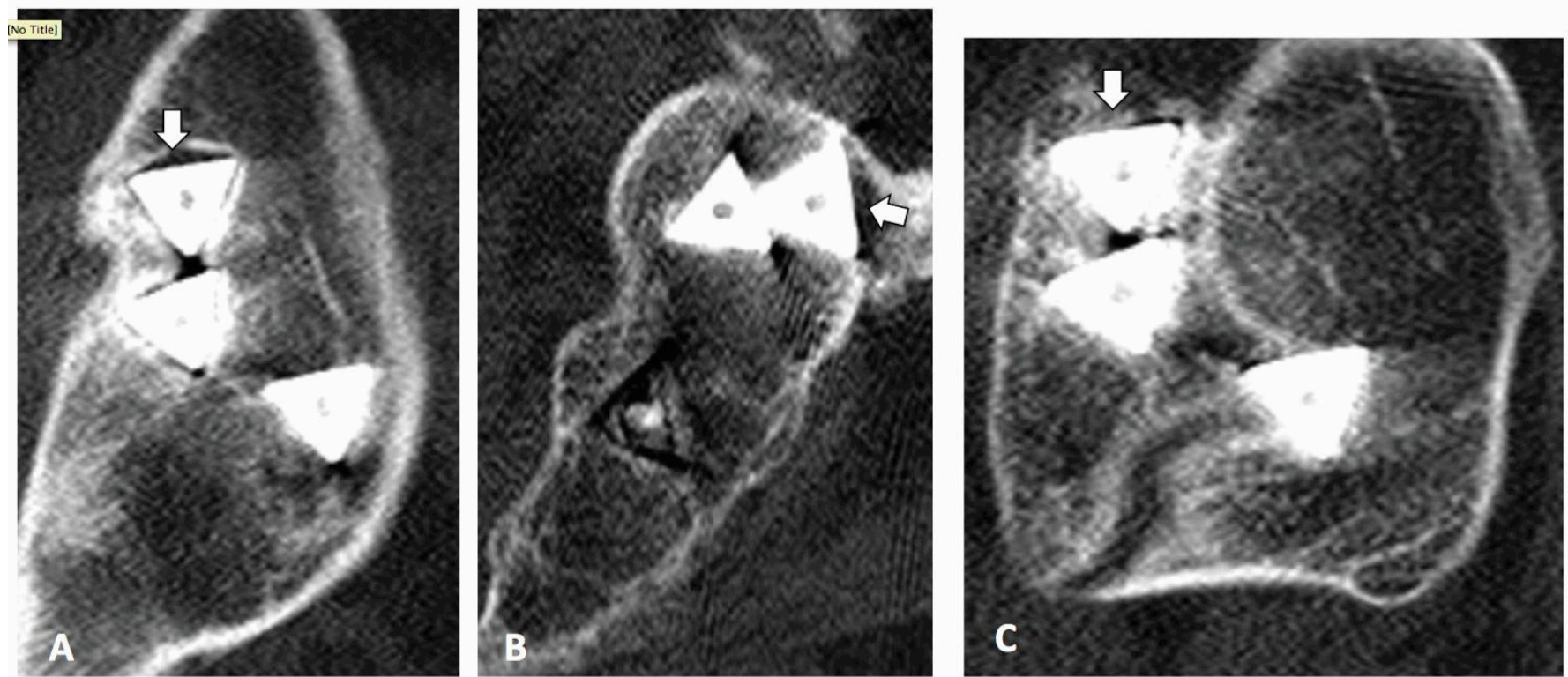

Fig. (5). A small area of focal lucency is observed along the superior edge of the most cranial implant on the iliac side (A), and along only part of the sacral side (B) as evidenced by circumferential bone observed on image (C).
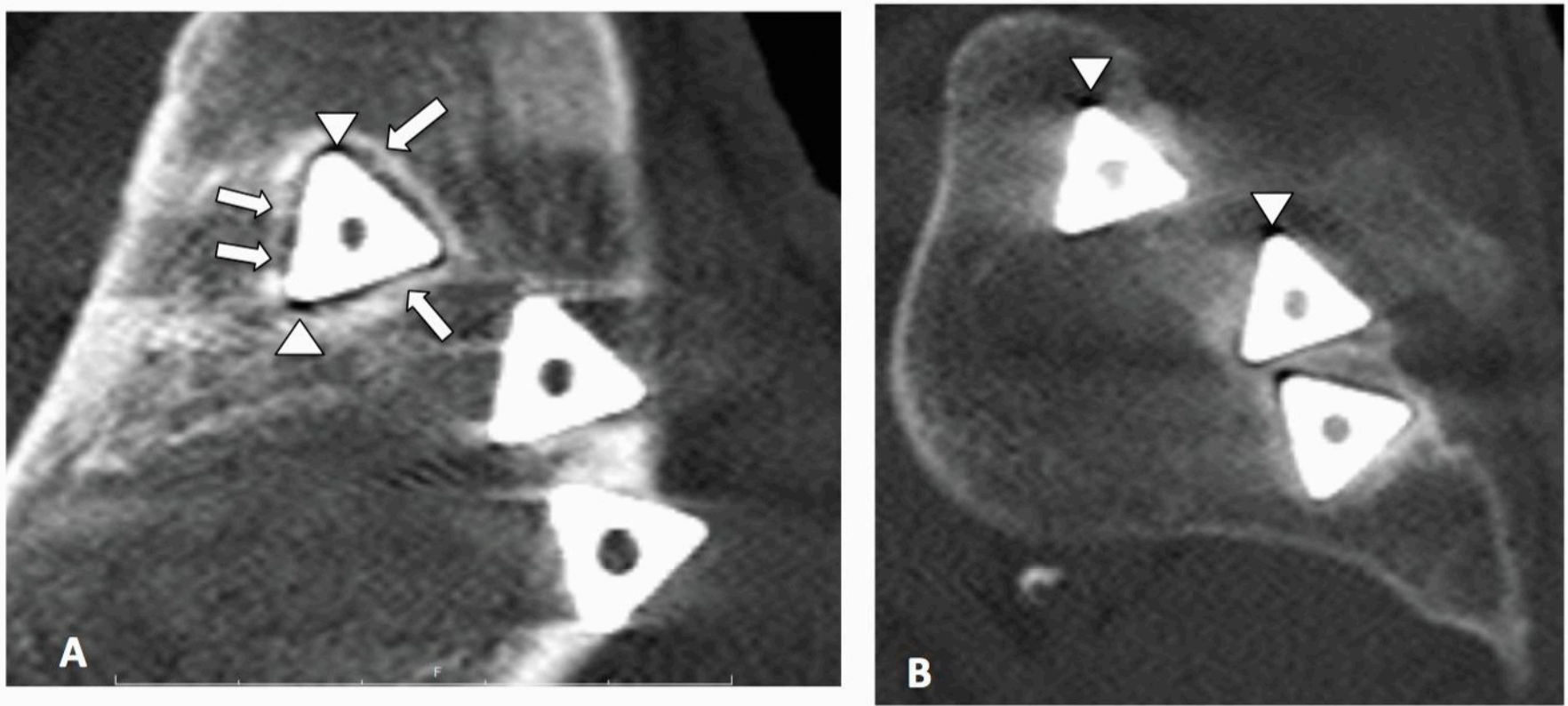

Fig. (6). (A) Sagittal CT scan of the iliac portion of the joint shows a sclerotic margin surrounding the edges of the superior implant. Areas of "spot-welds" (arrows) noted between the sclerotic margin and implant walls is suggestive of biological fixation. Artifacts are apparent at the corners of the implant (triangle). (B) The sacral side shows increased bone density adjacent to the implant walls.

Subject 1013 is a 50 -year old female who presented to the clinic post L4-S1 arthrodesis with complex pain syndrome and concomitant chronic conditions requiring multiple medications to manage her pain. Furthermore, due to her diminished ambulatory capability, she required assistance in performing activities of daily living. Subject symptoms and findings on physical exam suggested degenerative sacroiliitis. The SI joint as a pain generator was confirmed by intra-articular SI joint injection. The subject underwent a single-side SI joint fusion. She experienced good pain improvement on the operative side, prompting her to undergo diagnostic testing on the contralateral side followed by SI joint fusion. Postoperatively, she experienced significant improvement in ambulation and capacity for activities of daily living and near complete resolution of her bilateral SI joint pain. One year later, her degenerative hip joint disease had progressed, resulting in a left-sided total hip replacement. This subject declined to participate in the imaging component of the study. The degradation of function and high ODI score at the 5-year assessment seems associated with recurrent spine-related low back pain.

Subject 1002 is a 50 -year old female who underwent left SI joint fusion for degenerative sacroiliitis after previous L4S1 instrumented arthrodesis for degenerative spondylosis and spondylolisthesis. Postoperatively, she suffered from an infected hematoma secondary to hematogenous seeding from 
recurrent diverticulitis that resolved after a 6-week course of intravenous antibiotics. Clinically, the process to control her infection overshadowed her improvement from SI surgery. Several years after her SI joint fusion, she was diagnosed with L3/4 adjacent segment disease and experienced partial pain relief after L3/4 laminectomy. At the 5-year visit, there were no imaging findings to suggest implant failure as explanation for the subject's residual pain. This subject reported symptoms in her contralateral SI joint and continuing symptoms from L3/4 that will likely require arthrodesis. Therefore, the lumbar pain generators and symptoms from her contralateral SI joint have influenced the degree of her functional improvement after the index procedure.

All 7 patients with the SI joint as the sole PG experienced good to excellent outcomes. In the 10 patients with multiple PGs, 7 had favorable outcomes while residual pain from secondary PGs eclipsed symptom relief in the remaining 3 patients. There were no distinguishing characteristics on imaging between responders and non-responders. Residual symptoms did not correlate with implant failure or lack of boney integration. Accordingly, no correlation between clinical and radiographic outcomes can be made.

\section{DISCUSSION}

The 5-year results of patients treated for degenerative sacroiliitis and/or SI joint disruptions with MIS SI joint fusion using a series of triangular TPS coated implants presented herein demonstrate the long-term durability of positive outcomes regarding pain relief, return to function, and satisfaction with surgery. Though pre-operative ODI scores were unavailable for the current case series, the published range for patients with SI joint disorders is 52.6$61.8[23,24,31]$. Our mean 5 -year postoperative ODI score (21.5) indicates minimal to moderate impact on functional capacity, and is commensurate with results from other published studies. Long-term complications of MIS SI joint fusion were rare. No subject underwent revision of SI joint arthrodesis. Similar to other reports, a large portion (47\%) of patients in the present cohort had a history of previous lumbar spinal fusion. In contrast to a report describing the use of hollow modular anchorage screws, the degree of pain improvement for patients in the current study was not affected by a history of prior lumbar spinal fusion [19]. As with all studies, we observed variations in patient outcomes. In the current cohort, the number of pain generators, either single or multiple, influenced patient perception of improvement in pain and function after surgery. Amongst subjects who did not respond, multiple pain generators (PG) were apparent. Determination of primary versus secondary pain generators is critical in patients that present with multiple PGs.

Imaging studies at 5 years postoperatively revealed no evidence of implant loosening, confirmed by a consistent observation of increased bone density immediately adjacent to all walls of all implants, suggestive of biological fixation in bone. The cause of the sclerotic bony margin often observed on the upper wall of the most cranial implant is unknown, but may be the result of a) impaction from broaching step of the procedure, $b$ ) micromotion after initial implant placement, or c) as a result of Wolff's law in response to higher loading conditions. Further investigation is needed to fully understand the mechanism. After close evaluation of the appearance of the implants on plain film radiographs and CT imaging, we have come to appreciate the difference between lucency along an implant wall and actual loosening of the device. An observation of apparent linear lucency along the wall, nose or shoulder of the implant on $\mathrm{x}$ ray did not correlate with true lucency on $\mathrm{CT}$ in the present study, but rather with an artifact generated by the titanium implant. In our experience, true loosening of the implant will result in the appearance of an enlarged gap between the implant and a sclerotic margin on both x-ray and CT (Fig. 7). If implant loosening is suspected, it is vital to correlate clinical symptoms with 3 views on CT to differentiate artifact, lucency and loosening.

Multiple non-surgical and surgical treatments for SI joint disorders are available. When non-surgical management fails to provide adequate relief of symptoms, surgical arthrodesis is an option. Published case series of various arthrodesis techniques (both open and MIS) report variable degrees of improvement in pain and function, with more invasive approaches reporting moderately high complications and non-unions [22]. MIS techniques overall report significant improvements in pain and function, but results vary with surgical technique and patient selection.

Positive clinical outcomes are based on accurate diagnosis and assessment of all potential pain generators in the lumbar spine, SI joint and hip. Correctly diagnosing SI joint disorders requires a rigorous approach to arrive at an accurate diagnosis. A detailed history, comprehensive physical examination, and an index of suspicion are required to formulate a differential diagnosis. The practitioner utilizes imaging and diagnostic testing for the process of inclusion/exclusion of the different diagnostic possibilities. Several pathophysiologic conditions that affect the lumbar spine-SI joint-hip axis can present similarly and typically low back pain patients have multiple pain generators. Biomechanical studies clearly show an interdependent kinematic relationship within the lumbopelvic hip complex, with changes in one structure affecting degree of motion and load within the entire complex [32]. Therefore, the SI joint should be evaluated as a potential pain generator in patients who fail to improve or experience late non-mechanical failures after lumbar arthrodesis. Pain and degeneration in the SI joint after lumbar arthrodesis has been reported to range between 43 and $75 \%[6,30,33,34]$. The relatively low success rate of spinal fusion, combined with the high incidence of diagnosable SI joint disorders in patients presenting with low back pain strongly suggests that the SI joint is often overlooked as a PG in this population [3]. An accurate diagnosis requires not only a ruling out or downgrading of other conditions, but also a thorough evaluation of the lumbar spine and hip, as well as a physical exam that includes maneuvers that stress the SI joint and a series of image-guided intra-articular diagnostic injections.

For patients with multiple pain generators, the most bothersome should be treated first to assess the true impact of the secondary pain generator(s). Surgical treatment of the primary PG alone may effectuate adequate pain control in certain patients, while for others sequential treatment of secondary PGs may be indicated to achieve a satisfactory 

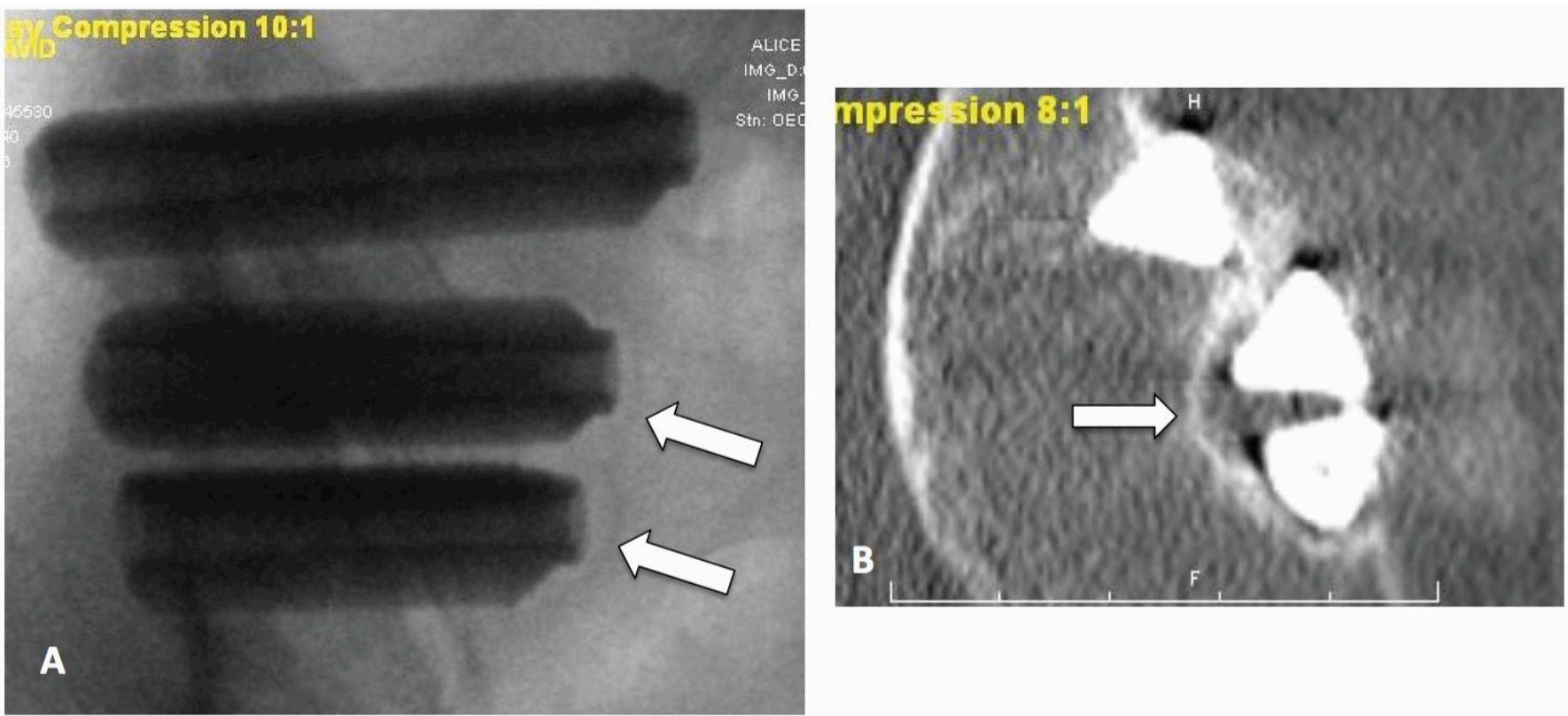

Fig. (7). A) AP X-ray and B) axial CT image of a non-study patient showing a wide gap between the edge of the implant and the sclerotic margin, indicative of implant loosening. This patient returned for revision surgery.

final outcome. Patients with multiple pain generators, regardless of treatment, may not experience a high degree of improvement as the cortical region of the sensory homunculus governing the low back and hip is relatively small, making it difficult for the brain to distinguish discrete pain generators in this area [35]. Functional improvement relies on the interdependent relationship of the lumbar spine, pelvis and hip axis. Pain or loss of function in one component can overshadow improvement in another. Identification and sequential treatment of secondary pain generators in this axis may be needed to achieve the best possible outcome.

Although the study sample size is relatively small and represents the experience of a single surgeon, this cohort represents the first patients to have received this implant. ODI was available only at the 5-year time point; a comparison to baseline could not be performed. It should be noted, however, that all pain and functional outcomes were self-reported by study subjects. Larger cohort and multicenter long-term studies are needed to better understand how to formulate a surgical strategy and set realistic outcome expectations in the patient with multiple pain generators within the lumbar spine-SI joint-hip axis.

\section{CONCLUSION}

Long-term (5-year) clinical and radiographic outcomes after MIS SIJ fusion for degenerative sacroiliitis and/or SI joint disruptions are favorable. Clinical improvements observed at 12 months postoperatively were maintained at 5years. There was no evidence of long-term complications, implant migration or loosening. Increased bone density was observed circumferentially in $100 \%$ of the implants. Most $(87 \%)$ scans showed intra-articular osseous bridging. Patients who did not do well were affected by multiple severe degenerative conditions of the spine, pelvis, and/or hip.

\section{CONFLICT OF INTEREST}

LR is an SI-BONE, Inc. investor, consultant and clinical trial investigator. RC is an SI-BONE, Inc. employee.

\section{ACKNOWLEDGEMENTS}

The authors wish to thank John Thibodeau, RN, BSN for his invaluable contributions to this study in conducting patient assessments and gathering clinical data, as well as Daniel Cher, MD for statistical advice. This study was funded by SI-BONE, Inc.

\section{REFERENCES}

[1] Vos T, Flaxman AD, Naghavi M, et al. Years lived with disability (YLDs) for 1160 sequelae of 289 diseases and injuries 1990-2010: a systematic analysis for the Global Burden of Disease Study 2010 Lancet 2012; 380(9859): 2163-96.

[2] Schwarzer AC, Aprill CN, Bogduk N. The sacroiliac joint in chronic low back pain. Spine 1995; 20(1): 31-7.

[3] Sembrano JN, Polly DW. How often is low back pain not coming from the back? Spine 2009; 34(1): E27-32.

[4] Maigne JY, Aivaliklis A, Pfefer F. Results of sacroiliac joint double block and value of sacroiliac pain provocation tests in 54 patients with low back pain. Spine 1996; 21(16): 1889-92.

[5] Bernard TN, Kirkaldy-Willis WH. Recognizing specific characteristics of nonspecific low back pain. Clin Orthop Relat Res 1987; (217): 266-80

[6] Slinkard N, Agel J, Swiontkowski MF. Documentation of outcomes for sacroiliac joint fusion: does prior spinal fusion influence the outcome? Eur Spine J 2013; 22(10): 2318-24.

[7] Slipman CW, Shin CH, Patel RK, et al. Etiologies of failed back surgery syndrome. Pain Med 2002; 3(3): 200-14; discussion 214-7.

[8] Bolt PM, Wahl MM, Schofferman J. The Roles of the hip, spine, sacroiliac joint, and other structures in patients with persistent pain after back surgery. Seminars Spine Surg 2008; 20(1): 14-9.

[9] Foley BS, Buschbacher RM. Sacroiliac joint pain: anatomy, biomechanics, diagnosis, and treatment. Am J Phys Med Rehabil 2006; 85(12): 997-1006.

[10] Broadhurst NA, Bond MJ. Pain provocation tests for the assessment of sacroiliac joint dysfunction. J Spinal Disord 1998; 11(4): 341-5 
[11] Cher D, Polly D, Berven S. Sacroiliac Joint pain: burden of disease. Med Devices (Auckl) 2014; 7: 1-9.

[12] Ackerman SJ, Polly DW Jr, Knight T, Holt T, Cummings J, Jr. Nonoperative care to manage sacroiliac joint disruption and degenerative sacroiliitis: high costs and medical resource utilization in the United States Medicare population. J Neurosurg Spine 2014; 20(4): 354-63.

[13] Ackerman S, Polly DW, Holt T, Cummings JT, Knight T. Management of sacroiliac joint disruption and degenerative sacroiliitis with nonoperative care is medical resource-intensive and costly in a United States commercial payer population. Clinicoecon Outcomes Res 2014; 2014(6): 63-74.

[14] Moore MR. Surgical treatment of chronic painful sacroiliac joint dysfunction. Movement, stability, and low back pain: the essential role of the pelvis. New York: Churchill Livingstone 1997; pp. 56372 .

[15] Waisbrod H, Krainick JU, Gerbershagen HU. Sacroiliac joint arthrodesis for chronic lower back pain. Arch Orthop Trauma Surg 1987; 106(4): 238-40.

[16] Lorio MP, Polly DW Jr, Ninkovic I, Ledonio CGT, Hallas K, Andersson G. Utilization of Minimally Invasive Surgical Approach for Sacroiliac Joint Fusion in Surgeon Population of ISASS and SMISS Membership. Open Orthop J 2014; 8: 1-6.

[17] Rudolf L. Sacroiliac Joint Arthrodesis-MIS Technique with Titanium Implants: Report of the First 50 Patients and Outcomes. Open Orthop J 2012; 6(1): 495-502.

[18] Khurana A, Guha AR, Mohanty K, Ahuja S. Percutaneous fusion of the sacroiliac joint with hollow modular anchorage screws: clinical and radiological outcome. J Bone Joint Surg Br 2009; 91(5): 627-31.

[19] Mason LW, Chopra I, Mohanty K. The percutaneous stabilisation of the sacroiliac joint with hollow modular anchorage screws: a prospective outcome study. Eur Spine J 2013; 22(10): 2325-31.

[20] Abumi K, Saita M, Iida T, Kaneda K. Reduction and fixation of sacroiliac joint dislocation by the combined use of S1 pedicle screws and the galveston technique. Spine 2000; 25(15): 1977-83.

[21] Wise CL, Dall BE. Minimally invasive sacroiliac arthrodesis: outcomes of a new technique. J Spinal Disord Tech 2008; 21(8): $579-84$.

[22] Graham Smith A, Capobianco R, Cher D, et al. Open versus minimally invasive sacroiliac joint fusion: a multi-center comparison of perioperative measures and clinical outcomes. Ann Surg Innov Res 2013; 7(1): 14

[23] Duhon B, Cher D, Wine K, Lockstadt H, Kovalsky D, Soo C-L. Safety and 6-month effectiveness of minimally invasive sacroiliac joint fusion: a prospective study. Medical Devices: Evidence Res 2013; 6: 219-29.

[24] Cummings J Jr, Capobianco RA. Minimally invasive sacroiliac joint fusion: one-year outcomes in 18 patients. Ann Surg Innov Res 2013; 7(1): 12

[25] Sachs D, Capobianco R. Minimally invasive sacroiliac joint fusion: one-year outcomes in 40 patients. Adv Orthop 2013; 2013: 536128.

[26] R Core Team. R: A Language and Environment for Statistical Computing [Internet]. Vienna, Austria: R Foundation for Statistical Computing; 2013. Available from: http: //www.R-project.org/

[27] Copay AG, Glassman SD, Subach BR, Berven S, Schuler TC, Carreon LY. Minimum clinically important difference in lumbar spine surgery patients: a choice of methods using the Oswestry Disability Index, Medical Outcomes Study questionnaire Short Form 36, and pain scales. Spine J 2008; 8(6): 968-74.

[28] Glassman SD, Copay AG, Berven SH, Polly DW, Subach BR, Carreon LY. Defining Substantial Clinical Benefit Following Lumbar Spine Arthrodesis. J Bone Joint Surg 2008; 90(9): 183947.

[29] Fairbank JC, Pynsent PB. The Oswestry Disability Index. Spine 2000; 25(22): 2940-52; discussion 2952

[30] Liliang P-C, Lu K, Liang C-L, Tsai Y-D, Wang K-W, Chen H-J. Sacroiliac joint pain after lumbar and lumbosacral fusion: findings using dual sacroiliac joint blocks. Pain Med 2011; 12(4): 565-70.

[31] Ledonio CGT, Polly DW, Swiontkowski MF. Minimally Invasive Versus Open Sacroiliac Joint Fusion: Are They Similarly Safe and Effective? Clin Orthop Relat Res 2014; 472(6): 1831-8.

[32] Sizer PS, Phelps V, Thompsen K. Disorders of the sacroiliac joint. Pain Pract 2002; 2(1): 17-34.

[33] DePalma MJ, Ketchum JM, Saullo TR. Etiology of Chronic Low Back Pain in Patients Having Undergone Lumbar Fusion. Pain Med 2011; 12(5): 732-9.

[34] Ha K-Y, Lee J-S, Kim K-W. Degeneration of sacroiliac joint after instrumented lumbar or lumbosacral fusion: a prospective cohort study over five-year follow-up. Spine 2008; 33(11): 1192-8.

[35] Schott GD. Penfield's homunculus: a note on cerebral cartography. J Neurol Neurosurg Psychiatr 1993; 56(4): 329-33.

(C) Rudolf and Capobianco; Licensee Bentham Open.

This is an open access article licensed under the terms of the Creative Commons Attribution Non-Commercial License (http://creativecommons.org/licenses/by-nc/3.0/) which permits unrestricted, non-commercial use, distribution and reproduction in any medium, provided the work is properly cited. 